\title{
Growth impairment in very low birthweight children at 12 years: correlation with perinatal and outcome variables
}

\author{
Andrew Powls, Nicola Botting, Richard W I Cooke, David Pilling, Neil Marlow
}

\begin{abstract}
Institute of Child
Health,

Alder Hey Children's

Hospital,

Liverpool

A Powls

N Botting

RWI Cooke

Department of

Radiology,

Alder Hey Children's

Hospital

D Pilling

Department of Child Health,

St Michael's Hospital,

Bristol

N Marlow below the third centile and $33 \%$ below the tenth. Weight was appropriate for height, but there was a residual deficiency in OFC measurements after taking height into account. In the VLBW group smaller head size was associated with lower IQ and mathematics and reading scores.

Conclusions-Growth problems persist in VLBW children and final heights may be even more abnormal than present heights suggest. VLBW children have smaller OFCs than expected from their short stature alone and this may be associated with poorer educational and cognitive outcomes.

(Arch Dis Child 1996;75:F152-F157)
\end{abstract}

Correspondence to:

Dr Andrew Powls,

Institute of Child Health,

Alder Hey Children's

Hospital,

Hospital,

Eaton Road

Liverpool L12 2AP.

Accepted 12 July 1996

Keywords: bone maturity, standing height, occipitofrontal circumference, sitting height, skinfold thickness.

Children with low birthweights grow less well during early childhood than their normal birthweight peers. Dunn ${ }^{1}$ reviewed papers

\begin{abstract}
Aims-To compare the growth of very low birthweight (VLBW) children in early adolescence with that of their normal birthweight peers; to examine the role of factors contributing to growth-parental height, perinatal variables, bone maturity and sexual maturation; to examine the correlation between head growth and cognitive and educational outcome.

Methods-Standing and sitting heights, weight, occipito-frontal circumference (OFC), skinfold thicknesses and pubertal staging were assessed in 137 VLBW children and 160 controls at 11-13.5 years of age. Ninety six $(70 \%)$ of the VLBW children had their bone age assessed using the TW2 method. Reported parental heights were obtained by questionnaire. All children had standardised tests of cognitive and educational ability. Perinatal data had been collected prospectively as part of a longitudinal study.
\end{abstract}

Results-VLBW children had lower heights, weight, and OFC. Skinfold thicknesses were no different. The children's short stature was not accounted for by difference in parental height, degree of pubertal development, or by retarded bone age. Indeed, the TW2 RUS score was significantly advanced in the VLBW children. Using the bone ages to predict final adult height, $17 \%$ have a predicted height describing these trends dating from as early as $1919 .^{2}$ Dunn also found that low birthweight children had poorer growth during their first two years, especially those who were small for gestational age (SGA). ${ }^{1}$ Dunn, however, noted that these children tended to catch up during their first two years, a trend which was greater amongst the children whose birthweight had been appropriate for gestational age (AGA).

More recently, attention has focused on the incidence and natural history of growth failure among very low birthweight (VLBW) survivors of neonatal intensive care. Several studies show that many of these children grow poorly during their first few years of life. ${ }^{3-10}$ This deficit may be even more pronounced if the infants were of extremely low birthweight (ELBW $<1000 \mathrm{~g}),^{811}{ }^{12}$ or if their growth in utero was impaired. ${ }^{3413}$

The natural history of these abnormal growth patterns is less clear. Catchup growth during their early years has been shown in a number of studies, ${ }^{346}$ with one study of primary school children showing no residual differences in size ${ }^{14}$ Other studies have found little or no catchup growth. ${ }^{75}$ One of these studies ${ }^{15}$ also found poorer incremental growth among VLBW children from 5 to 8 years of age than controls, leading to increasing differences in size.

Although the differences may be small in absolute terms, ${ }^{15}$ such studies frequently find an excess of VLBW children with abnormally short statures. ${ }^{3-5} 15$ Artificial growth hormone may be appropriate in these children. Furthermore, poor growth may be predictive of poor neurodevelopmental outcome, ${ }^{6}{ }^{16}$ particularly in those children with smaller head size. ${ }^{17} 1820$

We are not aware of any study which evaluates the growth of VLBW children exposed to neonatal intensive care, beyond primary school age.

\section{Methods}

The population studied was a hospital based cohort of VLBW children treated at the Mersey regional neonatal unit. The cohort was derived from two groups of VLBW children recruited while in primary school. Both groups have already been part of separate neurodevelopmental follow up studies; they were combined in the present study to increase the numbers for analysis. The first group were children with a birthweight of $<1251 \mathrm{~g}$ and birth dates between January 1980 and June 1981 inclusive. These children had been seen at 6 and 8 
Table 1 Anthropometric measures: mean deficits of VLBW children's measurements compared with those of their normal birthweight peers

\begin{tabular}{lllllll}
\hline Measure & Boys $(n=68)$ & P value & Girls $(n=70)$ & Pvalue & All $(n=138)$ & $P$ value \\
\hline Height $(\mathrm{cm})$ & $3.8(0.9-6.7)$ & 0.01 & $4.4(1.9-6.9)$ & 0.001 & $4.1(2.2-6.0)$ & $<0.001$ \\
Sitting height & $1.3(-0.05-2.8)$ & 0.06 & $2.2(0.9-3.6)$ & 0.001 & $1.8(0.8-2.8)$ & $<0.001$ \\
Weight (kg) & $1.1(-1.8-4.1)$ & 0.46 & $3.8(0.69-7.1)$ & 0.018 & $2.5(0.3-4.5)$ & 0.024 \\
OFC (cm) & $0.7(0.18-1.2)$ & 0.009 & $1.1(0.53-1.6)$ & $<0.001$ & $0.89(0.5-1.3)$ & $<0.001$ \\
Skinfold (mm): & & & & & & \\
$\quad$ Triceps & $-0.62(-2.2-0.99)$ & 0.44 & $1.7(-0.11-3.5)$ & 0.066 & $0.54(-0.7-1.8)$ & 0.39 \\
$\quad$ Subscapular & $-1.9(-3.9-0.03)$ & 0.047 & $-0.4(-2.3-1.6)$ & 0.68 & $-1.2(-2.6-0.2)$ & 0.09 \\
\hline
\end{tabular}

years by Marlow and colleagues. ${ }^{21}{ }^{22}$ The second group comprised children with a birthweight of $<1501 \mathrm{~g}$, gestation of < 31weeks, and birth dates between January 1982 and November 1983 inclusive. These children had been seen at 6 y ears of age by AM Davies. ${ }^{23}$ None of the children had any major neurodevelopmental handicap, and at the time of the original study were in mainstream schools. Altogether, the group studied comprised 137 VLBW children.

A normal birthweight control population was recruited, at the time of the initial studies, from classmates of the same sex and similar age to the VLBW children. This provided close matches for socioeconomic as well as educational variables at the time. These original controls were also traced and, where possible, used for the present study. As the overall study also looked at educational and cognitive outcome, VLBW children who were now at different schools from their controls had a new control selected from their present school to match for educational experience. Overall, 160 control children were assessed of whom 100 were original controls.

Informed written consent was obtained from the parents of all the children involved in the study. The children were seen and assessed in their schools.

Standing and sitting heights were measured using a portable stadiometer (Height stick, Nottingham Rehab) using a standard technique. Weight was measured on standard electronic scales in light indoor clothing. OFC was measured using a flexible tape measure. Subscapular and triceps skinfold thicknesses were measured using Holtain callipers in the manner described by Tanner et al. ${ }^{24}$ Pubertal staging was assessed as described before by Tanner, ${ }^{25}$ in all children and we ascertained the date of their first period for those girls who had reached menarche. Bone age was assessed in the VLBW children where parental consent was obtained for a wrist $x$ ray picture; this was performed shortly after the anthropometric measurements. All $x$ ray pictures were assessed by a single observer (DP) using the TW2 method. ${ }^{26}$ In view of the age of the children at the time of examination, expected adult heights were estimated using the TW2 RUS score. ${ }^{26}$ Parental heights were obtained from a health questionnaire given to all parents.

Perinatal data, including cranial ultrasound results, were taken from the neonatal intensive care records of the VLBW children.

Cognitive and educational outcomes were assessed using the following measures: a short form of the Wechsler Intelligence Scale for
Children-WISC III ${ }^{27}$; Wechsler Objective Reading Dimensions - WORD ${ }^{28}$; The NFER Basic Maths test. ${ }^{29}$

For the anthropometric measures, mean differences were analysed using non-paired $t$ tests. Pubertal staging was compared using MannWhitney U tests. To compare the children's heights with those of their parents, all heights were expressed as standard deviation scores (SDS) using the 1990 growth standards, ${ }^{30}$ and analysed using paired $t$ tests. Multiple regression models were used where multivariate analysis was required.

\section{Results}

There was no difference in the ages of the groups, median age at the time of assessment being 142 months (132-163) for the VLBW children and 143 (130-164) for the controls $\mathrm{P}=0.85$ (Mann Whitney). We obtained agreement for an $x$ ray picture to estimate bone age from $96(70 \%)$ of the VLBW children. There was no significant difference in height between those VLBW children who had an assessment of their bone age compared with those who did not, the mean difference in height being $0.71 \mathrm{~cm}$ ( $95 \%$ confidence interval (CI) -1.86 to $3.94 \mathrm{~cm} ; \mathrm{P}=0.48$ ). Details of maternal heights were obtained for 124 (89\%) VLBW children and $146(89 \%)$ controls, and paternal heights for $120(87 \%)$ VLBW children and $141(86 \%)$ controls.

\section{STANDING HEIGHT}

The VLBW children were significantly shorter than their normal birthweight peers with a mean deficit of $4.1 \mathrm{~cm}(95 \%$ CI $2.5-6.0 \mathrm{~cm}$; $P<0.001)$. The difference was greater for the girls than for the boys, but this difference was not significant (table 1). To control for their different ages, their standing heights were converted to standard deviation scores (SDS) using the 1990 growth reference data. ${ }^{30} \mathrm{Re}-$ peating the above analysis we demonstrated a mean deficit in the height of the VLBW children of 0.48 SD (95\% CI $0.34-0.79$; $P<0.001$ ). The distribution of heights (SDS) is illustrated in fig 1. A greater number of VLBW children are of short stature with $10 / 138(7 \%)$ being below the 3 rd centile and $31 / 138(22.5 \%)$ below the 10 th compared with $3 / 162$ (2\%); $\mathrm{P}=0.008$ and $14 / 162$ (9\%); $\mathrm{P}=0.0008$ controls, respectively.

\section{SITTING HEIGHT}

The sitting height of the VLBW children was also significantly less than that of the controls with a mean deficit of $1.8 \mathrm{~cm}(95 \%$ CI $0.8-2.8$ $\mathrm{cm} ; \mathrm{P}<0.001)$. When multivariate analysis 

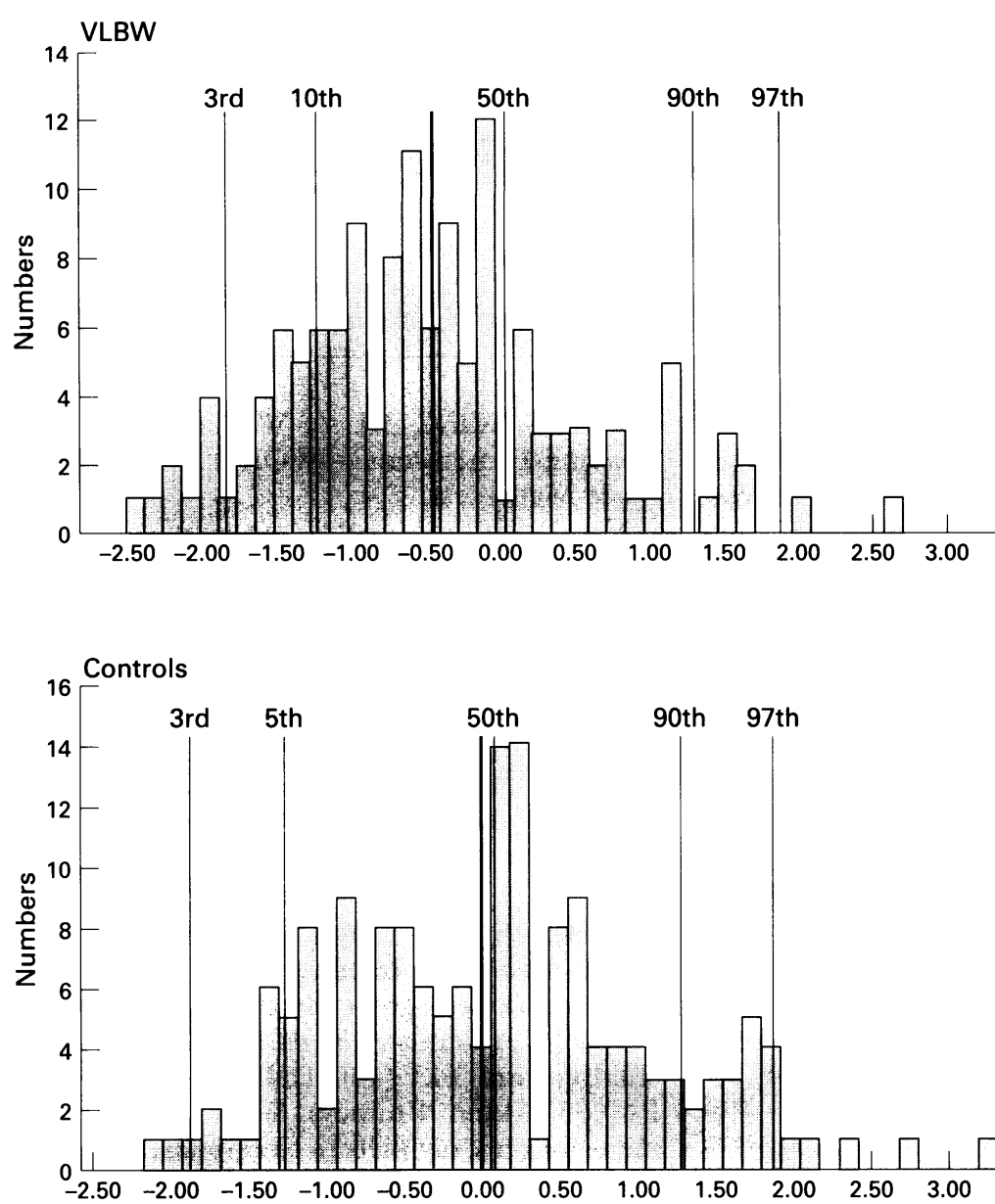

Figure 1 Heights at 11 to 13.5 years (expressed as standard deviation scores) in VLBW $(n=137)$ and control children $(n=160)$. Thin lines indicate centile equivalents; thick vertical bar indicates mean value.

was performed using standing height as an independent variable, however, there was no residual difference in sitting height. The sitting and standing heights of the VLBW children, therefore, were not disproportionate.

\section{WEIGHT AND SKINFOLD THICKNESS}

The VLBW children were also significantly lighter than their normal birthweight peers, with a mean difference of $2.5 \mathrm{~kg}(95 \%$ CI $0.3-$ $4.7 \mathrm{~kg} ; \mathrm{P}=0.024)$. This difference was more pronounced in girls (table 1). As with sitting height, on multivariate analysis this difference was accounted for by the differences in standing height. This indicates that the VLBW children are not disproportionately thin. This was

Table 2 Pubertal staging

\begin{tabular}{llll}
\hline & VLBW & Controls & P value \\
\hline Boys: & $(\mathrm{n}=68)$ & $(\mathrm{n}=79)$ & \\
Pubic hair > stage 1 & $27(40 \%)$ & $31(37 \%)$ & \\
$\quad$ Median stage (interquartile) & $1(1-2)$ & $1(1-2)$ & $\mathrm{P}=0.92$ \\
Genitals > stage 1 & $37(54 \%)$ & $45(56 \%)$ & $\mathrm{P}=0.90$ \\
$\quad$ Median stage (interquartile) & $2(1-2)$ & $2(1-2)$ & $\mathrm{P}=0.4$ \\
Testicular volume > $3 \mathrm{~cm}^{3}$ & $45(65 \%)$ & $58(71 \%)$ & \\
$\quad$ Median volume (interquartile) & $5 \mathrm{~cm}^{3}(3-10)$ & $5 \mathrm{~cm}^{3}(3-10)$ & \\
Girls: & $(\mathrm{n}=69)$ & $(\mathrm{n}=81)$ & \\
Breasts > stage 1 & $50(72 \%)$ & $56(68 \%)$ & $\mathrm{P}=0.73$ \\
$\quad$ Median stage (interquartile) & $2(1-4)$ & $2(1-4)$ & \\
Pubic hair > stage 1 & $47(68 \%)$ & $51(62 \%)$ & $\mathrm{P}=0.66$ \\
$\quad$ Median stage (interquartile) & $2(1-4)$ & $2(1-4)$ & $\mathrm{P}=0.7$ \\
Menarche & $15(22 \%)$ & $20(24 \%)$ & \\
$\quad$ Median age at menarche & $12.0 \mathrm{yr}(11.2-12.3)$ & $12.0 \mathrm{yr}(11.2-12.3)$ & \\
\hline
\end{tabular}

$P$ values are derived from Mann-Whitney $U$ test for stages of puberty. $\chi^{2}$ is used for the number of boys showing testicular growth and the number of girls having reached menarche. confirmed by the lack of any significant differences between the groups in their skinfold thickness measurements (table 1).

OCCIPITO-FRONTAL CIRCUMFERENCE

Head circumference was also significantly smaller in the VLBW children, with a mean deficit of $0.89 \mathrm{~cm}(95 \%$ CI $0.5-1.2 \mathrm{~cm}$; $\mathrm{P}<0.001)$. Once again this difference was also greater in girls than boys (table 1 ). In contrast to the measurements of weight and sitting height, when this difference was analysed using multivariate analysis, the differences in standing height only accounted for part of the difference in head sizes between the groups. There remained a significant difference in head sizes between VLBW children and the controls of $0.47 \mathrm{~cm}(95 \%$ CI $0.12-0.80 \mathrm{~cm} ; \mathrm{P}=0.006)$, indicating that the VLBW children have disproportionately small heads.

PUBERTAL STAGING

The deficit in stature among the VLBW children was not accounted for by a delayed pubertal growth spurt. No difference was found between the VLBW children and the controls in the stage of pubertal development that they had achieved. Among boys there was no difference in the numbers with testicular growth (those with orchidometer volume of $4 \mathrm{ml}$ or greater).Among girls there was no difference in the numbers who had reached menarche, nor in the age at which menarche had occurred (table 2).

\section{PARENTAL HEIGHTS}

Mothers of the VLBW children for whom reported heights were available were shorter than mothers of controls (mean difference 2.1 $\mathrm{cm}(95 \%$ CI $0.5-3.6 \mathrm{~cm} ; \mathrm{P}=0.009))$. There were no significant differences between reported paternal heights (mean deficit $0.5 \mathrm{~cm}$ (95\% CI $-2.2-1.2 ; \mathrm{P}=0.56)$. To determine whether the difference in maternal heights accounted for the deficit in stature of the VLBW children, maternal height and the VLBW/control status were entered into multiple regression models with height as the dependent variable. Although some of the difference in stature was accounted for by the difference in maternal height, there remained a significant difference in height between the groups of $3.5 \mathrm{~cm}(95 \%$ CI $1.54-5.5 \mathrm{~cm})$; $\mathrm{P}=0.0004$ ).

The heights of both the VLBW children and those of their controls were compared with those of their parents by expressing both sets of heights as standard deviation scores (SDS). As expected from the general demographic increase in stature, the control children were growing taller than their parents, with greater height SDS values than those of either their mothers or their fathers (table 3 ). In contrast, VLBW children were not growing taller than their parents, their height SDS values being lower than those of their fathers and very similar to those of their mothers. 
Table 3 Differences in mean height SDS values for parents of VLBW children and controls

\begin{tabular}{|c|c|c|c|c|}
\hline & & Pairs & $\begin{array}{l}\text { Difference } \\
(95 \%(C I)\end{array}$ & P value \\
\hline VLBW & Mothers & & & \\
\hline-0.47 & -0.57 & 124 & 0.10 & 0.34 \\
\hline VLBW & Fathers & & & \\
\hline-0.49 & -0.27 & 120 & -0.22 & 0.05 \\
\hline Controls & Mothers & & & \\
\hline 0.12 & -0.22 & 146 & 0.34 & 0.001 \\
\hline Controls & Fathers & & & \\
\hline 0.11 & -0.20 & 141 & 0.30 & 0.002 \\
\hline
\end{tabular}

BONE AGE AND PREDICTED ADULT HEIGHTS

The bone age of the 96 VLBW children, in whom it was assessed, was advanced when compared with their chronological age (using the 1975 TW2 standards), ${ }^{26}$ the mean difference being 0.59 years $(95 \%$ CI $0.33-0.84$ years ). The TW2 RUS scores were used to predict their final adult heights using the equations of Tanner and Whitehouse. ${ }^{26}$

As their bone age is advanced, their predicted heights fall on lower centiles than their heights alone would have predicted. Of the children for whom $x$ ray pictures were available, sixteen $(17 \%)$ had predicted heights of less than the third centile and $31(33 \%)$ had predicted heights of less than the tenth centile;

Table 4 Regression coefficients for effect of head size on cognitive and educational outcomes

\begin{tabular}{llll}
\hline Outcome variable & Regression coefficient & $95 \% \mathrm{CI}$ & $\mathrm{P}$ value \\
\hline Performance IQ & 2.27 & $0.93-3.61$ & $\mathrm{P}=0.0008$ \\
Verbal IQ & 2.75 & $1.67-3.83$ & $\mathrm{P}<0.0001$ \\
Full scale IQ & 2.74 & $1.56-3.91$ & $\mathrm{P}<0.0001$ \\
Maths & 1.37 & $0.59-2.15$ & $\mathrm{P}=0.0005$ \\
Sight reading & 1.23 & $0.36-2.1$ & $\mathrm{P}=0.004$ \\
Spelling & 2.03 & $1.04-3.02$ & $\mathrm{P}=0.0001$ \\
Reading comprehension & 1.23 & $0.47-2.0$ & $\mathrm{P}=0.0006$
\end{tabular}

Regression coefficients represent change in IQ (or educational score) for each increment in head circumference of $+1 \mathrm{~cm}$. All outcomes have same standardised scoring system used for IQ tests with mean score of 100 and SD of 15 points.

this distribution is illustrated in (fig 2).

Their predicted adult heights were expressed as standard deviation scores (SDS) and compared with the heights of their parents. The VLBW children were failing to achieve their genetic growth potential, their predicted height SDS being lower than that of their mothers, mean difference -0.29 SD (95\% CI -0.04 to $-0.54 ; \mathrm{P}=0.025)$ and that of their

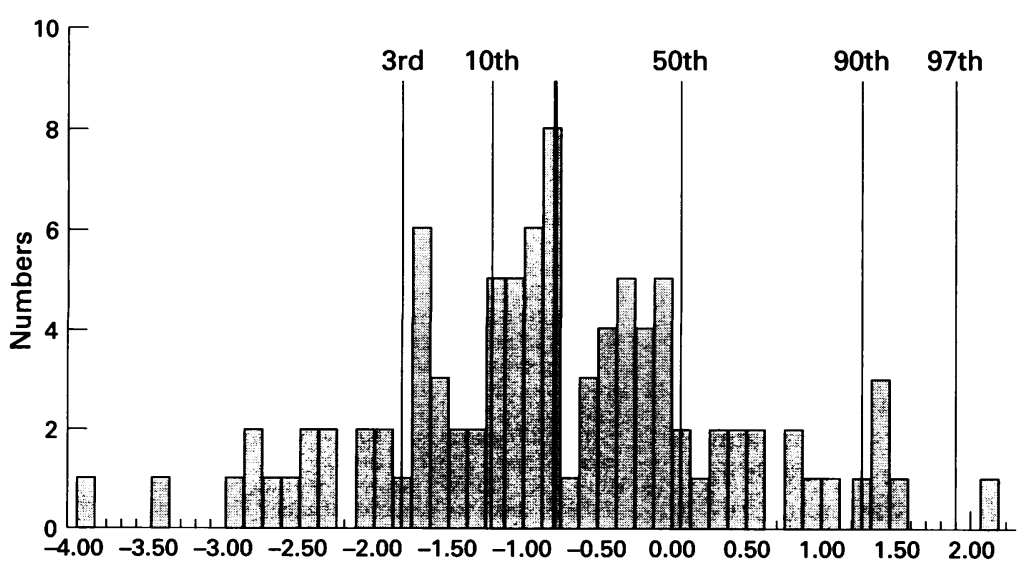

Figure 2 Predicted final adult heights (expressed as standard deviation scores) in VLBW children for whom bone ages were available. Thin lines indicate centile equivalents; thick vertical bar indicates mean value. fathers, mean difference $-0.58 \mathrm{SD}(95 \% \mathrm{CI}$ -0.30 to $-0.86 ; \mathrm{P}<0.001)$.

RELATION OF IMPAIRED GROWTH TO PERINATAL VARIABLES

In order to see if the impaired growth in height and OFC of the VLBW children could be predicted from adverse perinatal events, multiple regression models were constructed using these variables, expressed as SDS values as the dependent variables. The following perinatal variables were used in these models as independent variables: birthweight; birthweight for gestational age ${ }^{31}$ (expressed as standard deviation scores); extremely low birthweight (ELBW < 1000 g); gestation; sex; use of antenatal steroids; cystic periventricular leucomalacia; intraventricular haemorrhage (grade 2 or above); and neonatal convulsions.

Of these perinatal variables, only the birthweight SDS values were predictive of the VLBW children's heights at 12 years, but it accounted for only a tiny fraction of the variance $\left(r^{2}=0.029 ; P=0.0465\right)$. The presence of neonatal convulsions was associated with a reduced OFC, although this also predicted only a small fraction of the variance $\left(r^{2}=0.03\right.$; $P=0.03)$. No variables were predictive of the estimated final adult heights or the difference between the children's bone ages and their chronological ages.

\section{RELATION OF OFC TO COGNITIVE AND}

EDUCATIONAL OUTCOME VARIABLES

Head size was significantly associated with cognitive and educational outcome variables, those children with smaller heads having poorer outcomes in each of the measures used. The degree of effect of head size on these outcomes was assessed using a multiple regression model with OFC and their VLBW/control status as independent variables. Table 4 shows the regression coefficients for the change in scores for each $1 \mathrm{~cm}$ increment in head circumference.

\section{Discussion}

Our results show that VLBW children in early adolescence are still smaller than their normal birthweight peers. The stature of our controls very closely matched that of the normal population, unlike the VLBW children whose mean height fell significantly below. The mean deficit in stature in the VLBW group was around 3.8 $\mathrm{cm}$ and is similar to the difference found by Kitchen and colleagues in their study of 8 year old VLBW children. In contrast to their study, however, we found this difference to be no greater in the children with a birthweight of $<1000 \mathrm{~g}$ (ELBW).

The reason for the deficit in stature is not clear. The VLBW children seem to be entering puberty at the same time as their controls and, having entered puberty, seem to be progressing through their pubertal development at the same rate. Thus their deficit in stature cannot be accounted for by a late pubertal growth spurt. Furthermore, having smaller mothers accounts for only a small proportion of the deficit in the children's heights. If measured 
rather than reported maternal heights had been used in our study we may have found that maternal stature accounted for more of the deficit. This would only be the case, however, if there were a consistent trend towards overreporting of height among the mothers of the VLBW group only.

The possibility that retardation in bone age might account for shorter stature was suggested by Fitzhardinge et al, ${ }^{32}$ who observed retarded bone maturity in a group of 4 year old low birthweight children. In contrast to their study, however, the bone ages of our cohort were advanced compared with their chronological age (using the 1975 TW 2 standards). ${ }^{26}$ As the bone ages of the controls were not measured we cannot be certain that this is related to their low birthweight, or whether it is part of a demographic trend in bone maturation. However, this finding suggests that VLBW children may be shorter as adults than even their present heights suggest. Furthermore, this finding suggests that growth hormone would be of little use in these children, as growth hormone may further advance bone maturity and thus compromise even more their expected final stature.

Deficits in stature may only be clinically important for those individuals whose stature now, or as adults, is significantly below that of their peers. Our findings predict that as many as $17 \%$ of the VLBW population may fall below the 3rd percentile on attaining their final height.

We did not find the children to be disproportionately thin nor to have a disproportion between their sitting and standing heights. Although the raw measurements were smaller for the VLBW group, the differences were accounted for by their short stature on multivariate analysis. The VLBW children, however, did have disproportionately small heads. Short stature accounted for a small proportion of the differences in their head sizes, but a significant proportion remained unexplained. Measurement of OFC may underestimate the reduction in cranial volume as some VLBW children have persisting dolicocephaly, ${ }^{33}$ which produces larger measurements of circumference for a given volume than the normal rounder shape. "Flattened" dolicocephalic head shapes were still obvious in some of our cohort, but formal measurements were not made. Like some other authors, ${ }^{17} 1820$ we found the deficit in their head growth to be strongly correlated with poorer cognitive and educational outcome measures. Studies of malnourished children ${ }^{34}$ have shown that poor head growth correlates well with reduced brain growth and thus may be directly responsible for poorer cognitive outcomes.

Genetic factors are the major determinant of growth potential and we were able to show only weak associations between adverse perinatal factors in our VLBW group and their growth in adolescence. Birthweight for gestation correlated with height but only explained $3 \%$ of the variance, and this population contained mostly appropriately grown premature infants, with only $12(9 \%)$ below the 3rd centile at birth.
Therefore, this study does not provide useful data on long term growth after intrauterine growth impairment. The association between neonatal convulsions and poor head growth is similarly weak as convulsions occurred in only $12(9 \%)$

There may be perinatal factors involved in poor postneonatal growth not examined by this study. These may include antenatal growth rates, as not all babies born above the 3rd centile achieve their full growth potential in utero. Postnatal growth rates may also be important and may relate to postnatal nutrition. More subtle neurological damage than that visible on ultrasound scanning may also have contributed to poor head growth, and neonatal convulsions may simply be a marker for such damage.

At the time of writing, our cohort are now in early adolescence, with many having already started their pubertal development. Therefore, there is little potential for any further catchup growth to compensate for the impaired growth noted at this age. Indeed, their growth impairment may be more noticeable as they reach adulthood due to their advanced skeletal maturity. Further work is needed to see whether improved neonatal care, both in avoiding adverse perinatal events and in improving of neonatal nutrition, may alleviate subsequent growth impairment and whether improved head growth is associated with improved educational outcome.

This project was funded by the Medical Research Council.

We thank Mrs S Longworth and Mrs D Bolger for secretarial assistance and the schools who gave their time and facilities for our assessments.

1 Dunn HG. Sequelae of low birthweight:TheVancouver study. Clinics in Developmental Medicine No 95/96. Oxford: Mac Keith Press, 1986

2 Yloppo A. Das Wachstum der Fruhgeborenen von der geburt bis zum Schlalter. Zeitschrift für Kinderheilkunde 1919;24:111-78.

3 Hack M, Merkatz IR, Gordon D, Jones PK, Fanaroff AA. The prognostic significance of postnatal growth in very low-birth weight infants. Am $\mathcal{f}$ Obstet Gynecol 1982;143;693-9.

4 Hack M, Merkatz IR, McGrath SK, Jones PK, Fanaroff AA. Catch-up growth in very low birth weight infants. $A m \mathcal{F} D$ is Child 1984;138:370-4.

5 Kimble KJ, Ariagno RL, Stevenson DK, Sunshine P. Growth to age 3 years among very low birthweight sequelae-free survivors of modern neonatal intensive care. f Pediatr 1982;100: 622-4.

6 Astbury J, Orgill AA, Bajuk B, Yu VYH. Sequelae of growth failure in appropriate for gestational age, very low birthweight infants. Dev Med Child Neurol 1986;28:472-9.

7 Casey PH, Kraemer HC, Bernbaum J, Tyson JE, Sells C, Yogman MW, Bauer CR. Growth patterns of low birthweight preterm infants: A longitudinal analysis of a birthweight preterm infants: A longitudinal analys
large, varied sample. $\mathcal{F}$ Pediatr 1990;117:298-307.

8 Kitchen WH, Ford GW, Doyle LW. Growth and very low Kitchen WH, Ford GW, Doyle LW. Growth and

9 Ross G, Krauss AN, Auld PAM. Growth achievement in low birthweight premature infants: Relationship to neurobehavioral outcome at one year. $\mathcal{F}$ Pediatr 1983;103:105-8.

10 Saigal S, Rosenbaum P, Stoskopf B, Milner R. Follow up of infants 501 to $1500 \mathrm{gm}$ birthweight delivered to residents of a geographically defined region with perinatal intensive care facilities. f Pediatr 1982;100:606-12.

11 Teplin SW, Burchinal M, Johnson-Martin N, Humphry RA, Kraybill EN. Neurodevelopmental, health, and growth status at age 6years of children with birthweights less than 1001 grams. F Pediatr 1991;118:768-77.

12 Brothwood M, Wolke D, Gamsu H, Cooper D. Mortality, morbidity, growth and development of babies weighing diatr Scand 1988;77:10-18.

13 Vohr BR, Oh W. Growth and development in preterm infants small for gestational age. $尹$ Pediatr 1983;103:941-4. infants small for gestational age. F Pediatr 1983;103:941-4.
Ross G, Lipper EG, Auld PAM. Growth achievement of Ross G, Lipper EG, Auld PAM. Growth achievement of
very low birthweight premature children at school age. $\mathcal{F}$ Paediatr 1990;117:307-9.

15 Kitchen WH, Doyle LW, Ford GW, Callanan C. Very low birth weight and growth to age 8 years. I: Weight and height. Am $\mathcal{F}$ Dis Child 1992;146:40-5. 
16 Ross G, Krauss AN, Auld PAM. Growth achievement in low birth weight premature infants: Relationship to neurobebirth weight premature infants: Relationship to neurobe
havioral outcome at one year. $¥$ Pediatr 1983;103:105-8.

17 Kitchen WH, Doyle LW, Ford GW, Callahan C. Very low birth weight and growth to age 8 years. II: Head dimensions and intelligence. $A m \mathfrak{F} D$ is Child 1992;146:4650.

18 Hack M, Breslau N, Weissman B, Aram D, Klein N, Borawski $E$. Effect of very low birthweight and subnormal head size on cognitive abilities at school age. $N$ Engl f Med 1991; 325:231-7.

19 Simon NP, Brady NR, Stafford RL. Catch up head growth and motor performance in very low birthweight infants. and motor performance in verin

20 Gross SJ, Oehler JM, Eckerman.CO. Head growth and developmental outcome in very low birthweight infants. Pediatrics 1983;71:70-5.

21 Marlow N, Roberts BL, Cooke RWI. Motor skills in extremely low birthweight children at the age of 6 years. Arch Dis Child 1989;64:839-47.

22 Marlow N, Roberts BL, Cooke RWI. Outcome at 8 years for children with birthweights of $1250 \mathrm{~g}$ or less. Arch Dis Child 1993;68:286-90.

23 Ellis AM. Motor and attention skills in 6 year old extremely low birthweight infants $(<1500 \mathrm{~g})$ [Thesis], University of Liverpool, 1992.

24 Tanner JM, Whitehouse RH. Revised standards for triceps and subscapular skinfolds in british children. Arch Dis Child. 1975;50:142-5.

25 Tanner JM. Growth at adolescence. 2nd edn. Oxford: Blackwell scientific publications, 1962.

26 Tanner JM, Whitehouse RH, Marshall WA, Healy MJR, Tanner JM, Whitehouse RH, Marshall WA, Healy MJR,
Goldstein H. Assessment of skeletal maturity and prediction of adult height [TW II method]. London: Academic Press, 1975 .

27 Wechsler D. Wechsler intelligence scale for children - Third edition. San Antonio, Texas: The Psychological Corporation, 1992.

28 Wechsler D. Wechsler objective reading dimensions. San Antonio, Texas: The Psychological Corporation, 1993.

29 NFER. The basic maths test (DE and FG) London: NFER, 1969.

30 Freeman JV, Cole TJ, Chinn S, Jones PRM, White EM, Preece MA. Cross-sectional stature and weight reference curves for the UK 1990. Arch Dis Child 1995;73:17-24.

31 Keen DV, Pearse RG. Birthweight between 14 and 42 weeks gestation. Arch Dis Child 1985; 60:440-6.

32 Fitzhardinge PM, Steven EM. The small-for-date infant 1. Later growth patterns. Paediatrics 1972;49:671-81.

33 Elliman AM, Bryan EM, Elliman AD, Starte D. Narrow heads of preterm infants - do they matter? Dev Med Child Neurol 1986;28:745-8.

34 Winick M, Rosso P. Head circumference and cellular growth of the brain in normal and marasmic infants. $\mathcal{F}$ Pediatr 1969;74:774. 